\title{
A randomised dose-response study of prophylactic Methoxamine infusion for preventing spinal-induced hypotension during Cesarean delivery
}

Feng Fu, Yu-wen Tang, Hong Chen, Cui-cui Jiao, Na Ma and Xin-zhong Chen *id

\begin{abstract}
Background: a-receptor agonists have been reported to be safe and effective for treating or preventing spinalinduced hypotension during cesarean delivery. As a pure $a_{1}$ adrenergic agonist, methoxamine has potential advantages of reducing myocardial oxygen consumption and protecting the heart in obstetric patients compared to phenylephrine. The aim of this study was to determine the optimal prophylactic methoxamine infusion dose that would be effective for preventing spinal-induced hypotension in $50 \%\left(E_{50}\right)$ and $95 \%\left(E D_{95}\right)$ of parturients.

Methods: Eighty parturients with a singleton pregnancy scheduled for elective cesarean delivery were randomly allocated to receive prophylactic methoxamine infusion at one of four different fixed-rates: $1 \mu \mathrm{g} / \mathrm{kg} / \mathrm{min}$ (group M1), $2 \mu \mathrm{g} / \mathrm{kg} / \mathrm{min}$ (group M2), $3 \mu \mathrm{g} / \mathrm{kg} / \mathrm{min}$ (group M3), or $4 \mu \mathrm{g} / \mathrm{kg} / \mathrm{min}$ (group M4). An adequate response was defined as absence of hypotension (maternal SBP $<80 \%$ of baseline or SBP $<90 \mathrm{mmHg}$ ). The values for $\mathrm{ED}_{50}$ and $\mathrm{ED}_{95}$ of prophylactic methoxamine infusion were determined by probit regression model. The outcomes of maternal hemodynamics and fetal status were compared among the groups.
\end{abstract}

Results: The calculated $\mathrm{ED}_{50}$ and $\mathrm{ED}_{95}$ (95\% confidence interval) of prophylactic methoxamine infusion dose were 2.178 (95\% Cl 1.564 to 2.680$) \mu \mathrm{g} / \mathrm{kg} / \mathrm{min}$ and 4.821 (95\% Cl 3.951 to 7.017$) \mu \mathrm{g} / \mathrm{kg} / \mathrm{min}$, respectively. The incidence of hypotension decreased with increasing methoxamine infusion dose $(15 / 20,11 / 20,7 / 20$ and 2/20 in group $M 1, M 2$, $\mathrm{M} 3$ and $\mathrm{M} 4$ respectively, $P<0.001)$. 1-min Apgar scores and umbilical arterial PaO2 were lower but umbilical arterial PaCO2 was higher in Group M1. No difference was found in the other incidence of adverse effects and neonatal outcomes among groups.

Conclusions: Under the conditions of this study, when prophylactic methoxamine infusion was given at a fixedrate based on body weight for preventing spinal-induced hypotension in obstetric patients, the values for $\mathrm{ED}_{50}$ and $\mathrm{ED}_{95}$ were $2.178 \mu \mathrm{g} / \mathrm{kg} / \mathrm{min}$ and $4.821 \mu \mathrm{g} / \mathrm{kg} / \mathrm{min}$ respectively.

Clinical trial registration: Chinese Clinical Trial Registry (ChiCTR), registry number of clinical trial: ChiCTR-1,800,01 8,988, date of registration: October 20, 2018.

Keywords: Cesarean delivery, Hypotension, Spinal anesthesia, Dose-response, Vasopressor, Methoxamine

\footnotetext{
* Correspondence: chenxinz@zju.edu.cn

Department of Anesthesia, Women's Hospital, Zhejiang University School of Medicine, Xueshi Rd 1\#, Hangzhou, China
}

(c) The Author(s). 2020 Open Access This article is licensed under a Creative Commons Attribution 4.0 International License, which permits use, sharing, adaptation, distribution and reproduction in any medium or format, as long as you give appropriate credit to the original author(s) and the source, provide a link to the Creative Commons licence, and indicate if changes were made. The images or other third party material in this article are included in the article's Creative Commons licence, unless indicated otherwise in a credit line to the material. If material is not included in the article's Creative Commons licence and your intended use is not permitted by statutory regulation or exceeds the permitted use, you will need to obtain permission directly from the copyright holder. To view a copy of this licence, visit http://creativecommons.org/licenses/by/4.0/ The Creative Commons Public Domain Dedication waiver (http://creativecommons.org/publicdomain/zero/1.0/) applies to the data made available in this article, unless otherwise stated in a credit line to the data. 


\section{Background}

Hypotension is a common complication caused by spinal anesthesia or combined spinal-epidural anesthesia for cesarean delivery [1], affecting up to $80 \%$ of patients if prophylactic vasopressors are not administered [2]. Both maternal and fetal/neonatal adverse effects are mostly correlated with severity and duration of post-spinal hypotension [3]. At present, the treatment of spinalinduced hypotension in obstetric patients relies on the use of vasopressors and intravenous crystalloid co-hydration; so the choice of vasopressors and the method of administration in obstetric patients are critical [4].. It is accepted that $\alpha$-agonist drugs are the most appropriate agents to treat or prevent spinal-induced hypotension. Among all vasopressors, phenylephrine now is recommended as a first-line drug due to the amount of supporting data [46]. As another $\alpha$-agonist drug, we think methoxamine is also suitable for obstetric patients.

Because the distributions of $\alpha_{1}$-adrenergic receptors on the surface of blood vessels are different in each part of human body, the organ's responses to vasopressors are also different $[7,8]$. The subtypes of $\alpha_{1}$-adrenergic receptors $\left(\alpha_{1-} \mathrm{AR}\right)$ are $\alpha_{1 \mathrm{~A}}, \alpha_{1 \mathrm{~B}}$ and $\alpha_{1 \mathrm{D}} ; \alpha_{1 \mathrm{~A}}$ and $\alpha_{1 \mathrm{~B}}$ are mainly distributed in peripheral blood vessels, while $\alpha_{1 \mathrm{D}}$ is predominant and functional in human epicardial coronary arteries [9]. Phenylephrine can activate all subtypes of $\alpha_{1}$-adrenergic receptors $\left(\alpha_{1 \mathrm{~A}}, \alpha_{1 \mathrm{~B}}\right.$ and $\left.\alpha_{1 \mathrm{D}}\right)$, whereas as a highly selective $\alpha_{1}$ adrenergic agonist, methoxamine activate only $\alpha_{1 \mathrm{~A}}$ and $\alpha_{1 \mathrm{~B}}$ [10-12]. Methoxamine has in theory less effect on myocardial contractility and consequently resulting in lower myocardial oxygen consumption when compared to phenylephrine. The heart protective effect of methoxamine may benefit for patients with coronary artery disease, but may not be necessary for healthy patients. Previous studies have suggested that methoxamine administered by continuous infusion is safe and effective for maintenance of hemodynamics [13, 14]. Methoxamine intermittent boluses or infusion have also been reported to be used in obstetric patients for prevention of spinal-induced hypotension [15, 16]. It has been well accepted that prophylactic infusion of a vasopressor is better than intermittent bolus use to prevent spinal-induced hypotension during cesarean delivery [3]. However, no previous studies about optimal doses for prophylactic methoxamine infusions have now been reported.

In the present study, we investigated different doses of prophylactic methoxamine infusion for preventing spinalinduced hypotension in obstetric patients. The aim of this study was to determine the optimal dose of prophylactic methoxamine infusion that would be effective for preventing hypotension in $50 \%\left(\mathrm{ED}_{50}\right)$ and $95 \%\left(\mathrm{ED}_{95}\right)$ of patients; secondary outcomes included maternal symptoms, haemodynamic changes and neonatal blood gas values.

\section{Methods}

\section{Ethics and patients}

After obtaining approval by the ethical review board of the Women's Hospital, School of Medicine, Zhejiang University (approval number 20180095), and the registration in a Chinese Clinical Trial Registry (ChiCTR) (registration number ChiCTR1800018988; principle investigator: Fu Feng, M.D.; date of registration: October 20, 2018), we conducted a randomized, double-blinded dose-response study. Written informed consent was obtained from all subjects participating in the trial. This study adheres to CONSORT guideline.

Eighty parturients, American Society of Anesthesiologists physical status $(\mathrm{ASA} \leq 2)$, with a singleton pregnancy scheduled for elective cesarean delivery were recruited. Patients were excluded if they had pre-existing or pregnancy-induced hypertension, diabetes mellitus, known cardiovascular or cerebrovascular disease, fetal abnormality, or contraindication to spinal anesthesia. The patients, whose body mass index $>30 \mathrm{~kg} / \mathrm{m}^{2}$, height $<150 \mathrm{~cm}$ or $>170 \mathrm{~cm}$, gestational age $<36$ weeks were also excluded from the study.

\section{Grouping}

Patients were randomly assigned into 4 groups based on computer-generated random number sheet. The patient in different group received one of four different fixedrate prophylactic methoxamine infusion regimens as follows: $1 \mu \mathrm{g} / \mathrm{kg} / \mathrm{min}$ (group M1), $2 \mu \mathrm{g} / \mathrm{kg} / \mathrm{min}$ (group M2), $3 \mu \mathrm{g} / \mathrm{kg} / \mathrm{min}$ (group M3), or $4 \mu \mathrm{g} / \mathrm{kg} / \mathrm{min}$ (group M4). The range of infusion doses was based on the drug instruction, the consensus of Chinese experts in clinical anesthesiology and the previously published descriptions [13-15]. To maintain blinding, the solutions of methoxamine were prepared in identical $50-\mathrm{mL}$ syringes by a co-investigator (Qian J P), who was not involved in data collection or clinical care of the patients. With the infusion rate predetermined to be set to $50 \mathrm{ml} / \mathrm{h}$, the appropriate concentration of methoxamine was prepared by diluting to a $50 \mathrm{ml}$ mixture with saline for each group. Then the milligram amounts of methoxamine were shown as follow: group $\mathrm{M} 1$, weight $(\mathrm{kg}) \times 0.06$; group $\mathrm{M} 2$, weight $(\mathrm{kg}) \times 0.12$; group $\mathrm{M} 3$, weight $(\mathrm{kg}) \times 0.18$; group M4, weight $(\mathrm{kg}) \times 0.24$.

\section{General management}

Patients were subjected to $8 \mathrm{~h}$ food deprivation and $2 \mathrm{~h}$ water deprivation before surgery, without preoperative treatment. After arrival in the operating room, patients were allowed to rest for several minutes before measurements were taken. Standard noninvasive monitoring was applied, including non-invasive BP, pulse oximetry, and electrocardiography. The baseline systolic blood pressure (SBP) and maternal heart rate (HR) were determined 
from the mean of three readings that fell within $10 \%$ of each other, taken at least one minute apart. An IV line was established with an 18-gauge IV cannula in the forearm, and an infusion of lactated Ringer's (LR) solution was started at a minimal rate to keep the vein open.

\section{Anesthesia procedures}

Combined spinal-epidural anesthesia was performed with patients in the left lateral position. Epidural anesthesia was performed at the $\mathrm{L} 1-2 ; 5 \mathrm{ml}$ of saline was injected into the epidural space before insertion of the epidural catheter; while spinal anesthesia (midline puncture) was performed at L3-L4 or L4-L5.We injected the mixed intrathecal solution $(1.5 \mathrm{ml}$ of $1 \%$ hyperbaric Ropivacaine $+1.5 \mathrm{ml}$ of $10 \%$ dextrose) into the subarachnoid space at the rate of $1 \mathrm{ml}$ per $10 \mathrm{~s}$. The $15 \mathrm{mg}$ dose of hyperbaric ropivacaine was chosen because it is close to the $\mathrm{ED}_{95}$ for cesarean section in Chinese parturients reported by Chen X Z et al. [17] Immediately after the injection of the intrathecal medication, infusion of study drug of methoxamine was started at dosages of $1,2,3$, and $4 \mu \mathrm{g} \cdot \mathrm{kg}^{-1} \cdot \mathrm{min}^{-1}(50 \mathrm{ml} / \mathrm{h})$ respectively. Simultaneously, a fluid coload with $15 \mathrm{ml} / \mathrm{kg}$ of lactated Ringer's solution over 20 to $30 \mathrm{~min}$ was started. Patients were then positioned supine with left uterine displacement and oxygen $5 \mathrm{~L} / \mathrm{min}$ was administered via a facemask. The sensory block level of anesthesia, assessed by loss of pin prick discrimination, was recorded 5 and $15 \mathrm{~min}$ after induction of spinal anesthesia. The tested upper sensitivity block to T6 was considered adequate for surgery. However, the decision to allow surgery to start was based on clinical judgment of the attending anesthesiologist. In this study, we didn't use the epidural catheter dose during the study period. If any patient received an epidural catheter dose, then they would have been excluded from the study.

\section{Monitoring and interventions}

As per our standard practice, SBP, heart rate, and pulse oximetry were assessed every minute, commencing immediately after intrathecal injection until delivery and subsequently at 5-min intervals. Hypotension was defined as a decrease in SBP less than $80 \%$ of baseline value or $\mathrm{SBP}<90 \mathrm{mmHg}$. If $90 \mathrm{mmHg} \leq \mathrm{SBP}<100$ $\mathrm{mmHg}$, it was treated with rapid infusion of lactated Ringer's solution; if the SBP was $<90 \mathrm{mmHg}$, it was treated with a bolus of $3 \mathrm{mg}$ IV methoxamine as rescue medication. Administration of a rescue bolus was repeated at 1-min intervals if hypotension persisted. We didn't stop the treatment until hypotension improves or tends to improve $[18,19]$. Reactive hypertension, defined as an increase in SBP to $\geq 20 \%$ above the baseline, was treated by stopping the infusion of methoxamine. Infusions were restarted only when the SBP decreased to <
$120 \%$ of baseline. Bradycardia was defined as a heart rate $<50$ beats/min; the bradycardia was managed by stopping the methoxamine infusion if no hypotension was present, and if hypotension was present during bradycardia then atropine $0.5 \mathrm{mg}$ was given.

As our standard practice, the study was commenced immediately after intrathecal injection, until delivery of the baby. An effective methoxamine infusion dose was defined by the outcomes that patient did not have hypotension throughout the study period.

\section{Data collection}

Additional data collection included maternal demographics: age, weight, height etc. Time of fetal exposure to anesthesia and to surgical procedures were evaluated as induction-delivery interval (time from intrathecal injection to delivery of the fetus) and uterine incision-delivery interval (time from uterine incision to delivery of the fetus). Episodes of hypotension, hypertension, bradycardia, nausea and vomiting and shivering were recorded. Neonatal Apgar scores were measured at $1 \mathrm{~min}$ and $5 \mathrm{~min}$. A segment of the umbilical cord was collected for assessment of blood gases in the umbilical artery. The timeline of the whole study [20] was shown as Fig. 1.

\section{Statistical analysis}

Sample size estimation was determined by the CochranArmitage Test using PASS ${ }^{\circ}$ (Version 11.0.7, NCSS, LLC, Kaysville, UT). According to and results from early preliminary data, the frequency of postspinal hypotension $(70,50,30$ and $10 \%$ respectively) in patients receiving one of the four infusion regimes same to that in the present study. The minimum effect size was 48 patients in total (12 patients per group), which was found to have $90 \%$ power to detect a linear trend using a $Z$ test with continuity correction and a significance level of 0.05 . Allowing for possible dropouts, the sample size was increased to 80 patients (20 patients per group).

Data were expressed as mean and $95 \%$ confidence interval [mean (1.96 SD), 95\% CI]. For numerical data, the Kolmogorov-Smirnov method was used to test for normal distribution, followed by one-way analysis of variance for normally distributed data and KruskalWallis test for non-normally distributed data among the groups with post Bonferroni tests for pairwise comparisons. For nominal data, statistical analysis was performed by means of the Cochran-Armitage chi-square test for trend.

Dose-response data were analyzed with probit regression. Dose values were entered as $\mathrm{x}$ values, $\mathrm{Y}$ was the response as a percentage. The regression coefficient was obtained by regression analysis, then the $\mathrm{ED}_{50}$ and $\mathrm{ED}_{95}$ values were obtained from interpolation of the linear 


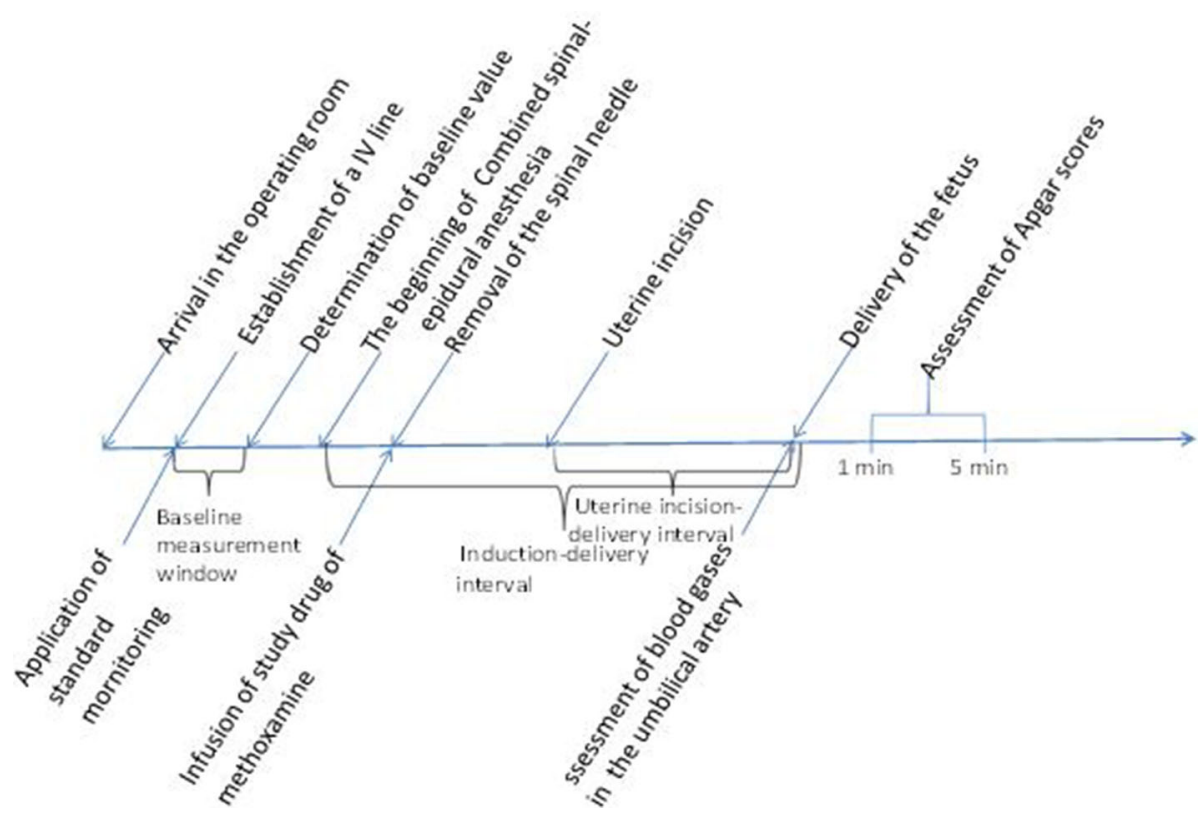

Fig. 1 Study timeline: The period from the patient's arrival in the operating room to the end of the study

probit regression plot, and generation of the sigmoid dose-response plot was obtained secondarily. Serial changes in systolic blood pressure (SBP) of four groups are shown for the first $12 \mathrm{~min}$ after spinal anesthesia; they were analyzed using two-way ANOVA (include: different time points in the same group and different groups in the same time point). The correlation between duration of hypotension and 1-min Apgar score, duration of hypotension and umbilical arterial $\mathrm{PaCO} 2$ were analysed using Spearman's rank correlation.

Analyses were performed using IBM SPSS Statistics for Windows version 22.0(IBM Corp, Armonk, NY) and GraphPad Prism version 5.0 (GraphPad Software Inc., San Diego, CA).All tests were two-tailed and $P$-value $<$ 0.05 was considered statistically significant.

\section{Results}

The trial flow diagram is shown in Fig. 2. A total of 88 parturients presenting for elective cesarean section were enrolled into the study; however, 4 patients did not meet the inclusion criteria, 3 patients had inadequate or failed spinal anesthesia and 1patient met too long U-D interval to analysis. Thus, the final analyses were confined to 80 parturients, with 20 subjects in each group. There were no significant differences among the groups in patient demographic characteristics, sensory block level, induction-delivery interval and uterine incision-delivery interval (Table 1.).

The incidence of intraoperative adverse events and physician interventions is presented as Table 2 . The incidence of hypotension decreased with increasing methoxamine dose $(75,55,35$ and 10\%; $p<0.0001)$; duration of hypotension also decreased along with group M1 to M4 $(p<0.0001)$. The incidence of reactive hypertension had an upward trend, but it was not statistically significant. There were no significant differences among the groups in the other incidences of adverse events including bradycardia, shivering and nausea and vomiting. The results showed the lower dose of methoxamine was used, the more rescue methoxamine bolus doses $(p=0.0001)$ and physician interventions (rescue vasopressor bolus, IV fluid bolus or atropine $0.5 \mathrm{mg}$ etc.) were required ( $p=0.0003$ ).

Serial changes in systolic blood pressure (SBP) for four groups in the first $12 \mathrm{~min}$ after spinal anesthesia (SA) are shown in Fig. 3. Analysis of SBP showed that changes in SBP were influenced significantly by both the dose of methoxamine and time $(P<0.05)$.

The dose-response curve of methoxamine infusions for preventing spinal-induced hypotension is calculated by probit regression model shown in Fig. 4. The values for $\mathrm{ED}_{50}$ and $\mathrm{ED}_{95}$ were 2.178 (95\% CI 1.564 to 2.680$) \mu \mathrm{g} / \mathrm{kg} / \mathrm{min}$ and 4.821 (95\% CI 3.951 to 7.017$) \mu \mathrm{g} / \mathrm{kg} / \mathrm{min}$, respectively.

Neonatal outcomes are presented in Table 3. 1-min Apgar scores were lower in group M1 $[9(8 \sim 10)](P<$ 0.01 ). The outcomes of umbilical arterial blood gases showed $\mathrm{PaO} 2$ was lower but $\mathrm{PaCO} 2$ was higher in group M1 $(P<0.01)$. However, there were no differences in umbilical arterial blood $\mathrm{PH}$ and base excess among groups. Correlation analysis (Fig. 5.) showed a negative correlation between duration of hypotension and 1-min Apgar score (Spearman's r: $-0.74, P<0.001$ ), but a positive correlation between duration of hypotension and umbilical arterial PaCO2 (Spearman's r: 0.33, $P<0.001$ ). 


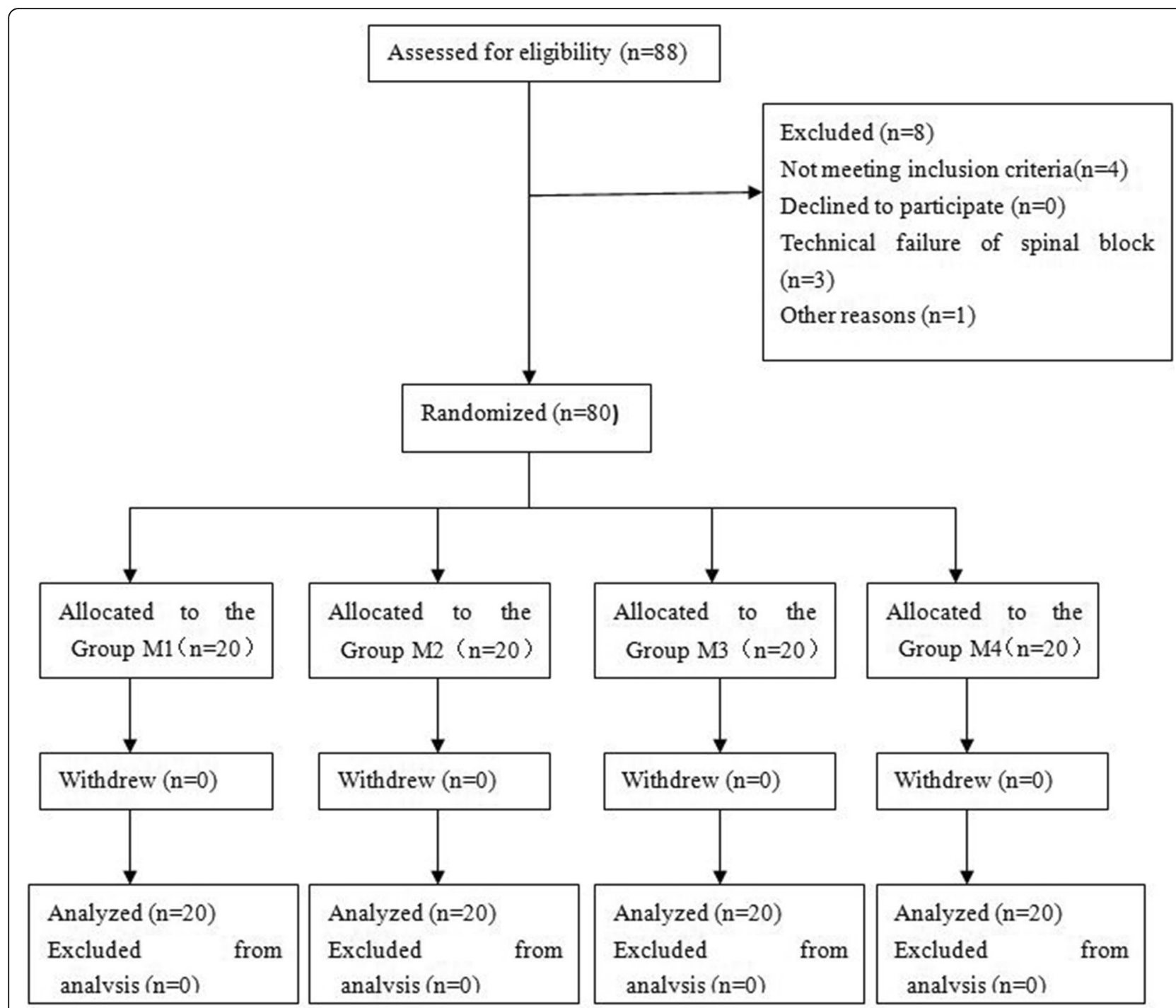

Fig. 2 The Consolidated Standards of Reporting Trials flow diagram: Enrollment, randomization, and allocation of the study subjects

Table 1 Patient characteristic data, sensory block level and surgical times

\begin{tabular}{|c|c|c|c|c|c|}
\hline & $\begin{array}{l}\text { Group M1 } \\
(n=20)\end{array}$ & $\begin{array}{l}\text { Group M2 } \\
(n=20)\end{array}$ & $\begin{array}{l}\text { Group M3 } \\
(n=20)\end{array}$ & $\begin{array}{l}\text { Group M4 } \\
(n=20)\end{array}$ & $P$ value \\
\hline Age $(y r)$ & $33.7 \pm 5.3$ & $34.3 \pm 4.1$ & $31.6 \pm 4.0$ & $32.8 \pm 3.7$ & 0.24 \\
\hline Weight (kg) & $67.0 \pm 6.7$ & $66.6 \pm 8.4$ & $65.2 \pm 7.1$ & $67.0 \pm 6.5$ & 0.83 \\
\hline Height (cm) & $161.0 \pm 3.3$ & $159.6 \pm 5.2$ & $158.7 \pm 3.9$ & $161.9 \pm 4.7$ & 0.09 \\
\hline $\mathrm{BMI}\left(\mathrm{kg} \mathrm{m}^{-2}\right)$ & $25.9 \pm 2.5$ & $26.1 \pm 2.5$ & $25.9 \pm 2.5$ & $25.4 \pm 2.4$ & 0.83 \\
\hline GA(wk) & $38(37 \sim 40)$ & $38(36 \sim 40)$ & $38(37 \sim 40)$ & $38(36 \sim 40)$ & 0.62 \\
\hline Sensory block level (dermatome) & $\mathrm{T} 4(\mathrm{~T} 4 \sim 6)$ & $\mathrm{T} 5(\mathrm{~T} 4 \sim 6)$ & $\mathrm{T} 4(\mathrm{~T} 4 \sim 6)$ & $\mathrm{T} 5(\mathrm{~T} 4 \sim 6)$ & 0.67 \\
\hline I-D interval(min) & $13.7 \pm 3.6$ & $13.7 \pm 2.8$ & $12.1 \pm 2.9$ & $12.6 \pm 2.7$ & 0.26 \\
\hline U-D interval(s) & $64.8 \pm 11.5$ & $61.9 \pm 16.0$ & $62.8 \pm 20.7$ & $64.5 \pm 16.4$ & 0.94 \\
\hline
\end{tabular}

Data are presented as mean \pm SD or median (range);

$G A$ gestational age, I-D interval: induction-delivery interval, U-D interval: uterine incision-delivery interval 
Table $\mathbf{2}$ The incidence of intraoperative adverse events and physician interventions

\begin{tabular}{|c|c|c|c|c|c|}
\hline & $\begin{array}{l}\text { Group M1 } \\
(n=20)\end{array}$ & $\begin{array}{l}\text { Group M2 } \\
(n=20)\end{array}$ & $\begin{array}{l}\text { Group M3 } \\
(n=20)\end{array}$ & $\begin{array}{l}\text { Group M4 } \\
(n=20)\end{array}$ & $P$ value \\
\hline Hypotension & $15(75 \%)$ & $11(55 \%)$ & $7(35 \%)$ & $2(10 \%)$ & $<0.0001$ \\
\hline Reactive hypertension & $0(0 \%)$ & $1(5 \%)$ & $2(10 \%)$ & $3(15 \%)$ & 0.058 \\
\hline Bradycardia & $3(15 \%)$ & $3(15 \%)$ & $3(15 \%)$ & $0(0 \%)$ & 0.154 \\
\hline Nausea and vomiting & $3(15 \%)$ & $1(5 \%)$ & $1(5 \%)$ & $2(10 \%)$ & 0.596 \\
\hline Shivering & $3(15 \%)$ & $0(0 \%)$ & $1(5 \%)$ & $0(0 \%)$ & 0.067 \\
\hline Duration of hypotension for per patient (min) & $2.0 \pm 1.5$ & $1.2 \pm 1.3$ & $0.7 \pm 1.0$ & $0.2 \pm 0.6$ & $<0.0001$ \\
\hline Number of patients who need rescue methoxamine bolus & $14(70 \%)$ & $9(45 \%)$ & $7(35 \%)$ & $2(10 \%)$ & 0.0001 \\
\hline Number of patients who need physician interventions & $15(75 \%)$ & $9(45 \%)$ & $9(45 \%)$ & $3(15 \%)$ & 0.0003 \\
\hline
\end{tabular}

Data are presented as number (\%), mean \pm SD or median (range); Categorical data were analyzed using the Cochran-Armitage chi-square test for trend Hypotension: SBP $<80 \%$ baseline or $<90 \mathrm{mmHg}$; Reactive hypertension: SBP $>120 \%$ of baseline value. Bradycardia: heart rate $<50$ beats/min

\section{Discussion}

In this prospective, randomized double-blinded study, the dose-response relationships for prophylactic methoxamine infusion in patients undergoing combined spinal-epidural anesthesia for elective cesarean delivery were determined. The calculated $\mathrm{ED}_{50}$ and $\mathrm{ED}_{95}(95 \%$ confidence interval) for an effective prophylactic methoxamine infusion dose were 2.178 (95\% CI 1.564 to $2.680) \mu \mathrm{g} / \mathrm{kg} / \mathrm{min}$ and 4.821 (95\% CI 3.951 to 7.017$) \mu \mathrm{g} /$ $\mathrm{kg} / \mathrm{min}$, respectively. This result may serve as a reference to guide for clinical infusion, but caution must be exercised because the calculated value of ED95 is above the maximum value tested.

In the present study, a probit regression model was used to determine values for $\mathrm{ED}_{50}$ and $\mathrm{ED}_{95}$. With this type of analysis, these values represent that the infusion dose of methoxamine would be effective for preventing hypotension in $50 \%\left(\mathrm{ED}_{50}\right)$ and $95 \%\left(\mathrm{ED}_{95}\right)$ of patients. According to these, the term $E D x$ refers to the dose those results in an effective response in $X \%$ of patients [6]. The dose-response studies of phenylephrine infusion have been reported many times, but this is the first time for us to investigate optimal methoxamine infusion dose based on patient's body weight by this means.

As we all know, the focus of how to prevent or treat spinal-induced hypotension has shifted to vasopressor drugs [21]. After decades of research, despite phenylephrine is currently considered a first-line vasopressor for prevention and treatment of spinal-induced hypotension during cesarean delivery, there are many other choices [22-24]. It is reported that norepinephrine and other alpha-adrenergic agonists have been chosen for management of spinal-induced hypotension during cesarean section. Methoxamine and phenylephrine have similar effects on vascular resistance, but methoxamine has relatively long duration of action and less potent [7]. What's more, methoxamine has the potential advantage of reducing myocardial ischemia and protecting the heart, and tachyphylaxis has seldom been observed in methoxamine compared to other vasopressors [25]. Therefore, methoxamine is often used to maintain stable hemodynamics and suitable for elderly patients. However, the use of methoxamine in obstetrics was rare due to its

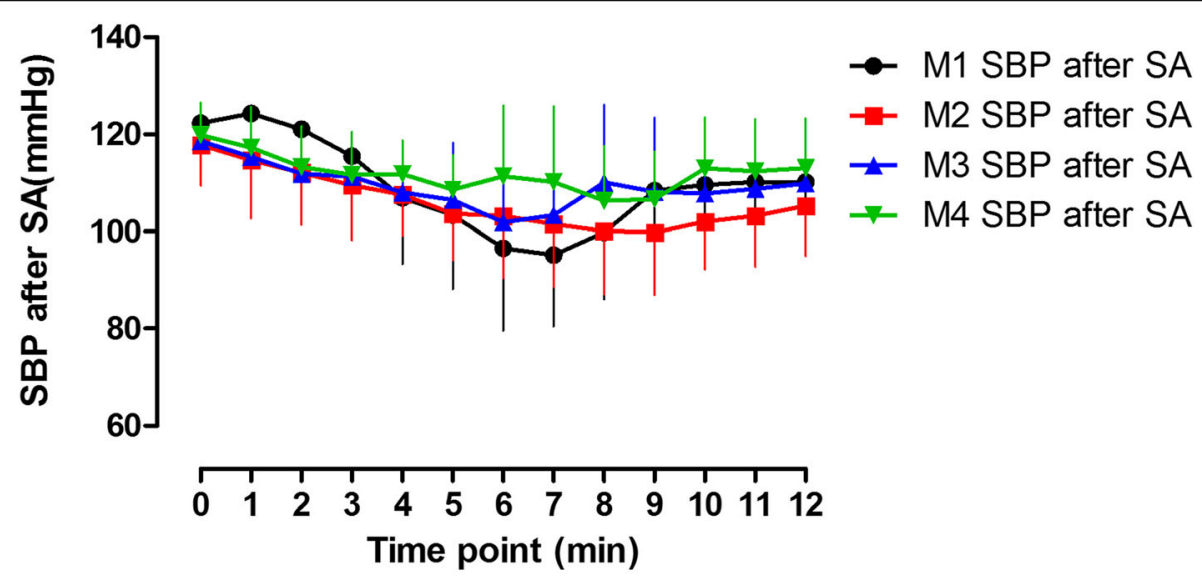

Fig. 3 Serial changes in systolic blood pressure (SBP). Data are represented as mean (standard deviation) and are shown for the first 12 min after spinal anesthesia (SA) only. The data (mean SBP +/- SD.) over time was significantly different among groups $(P<0.001)$. 


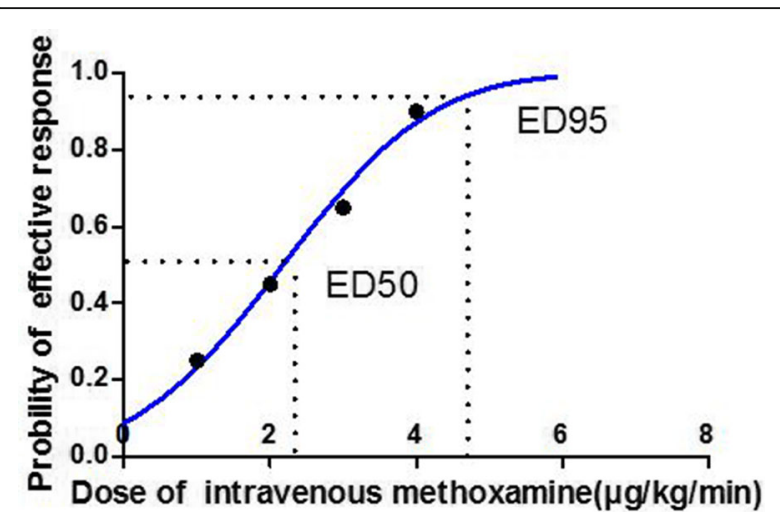

Fig. 4 The dose-response curve of methoxamine infusions for preventing hypotension. The values for ED50 and ED95 calculated by Probit regression model were $2.178(95 \% \mathrm{Cl} 1.564$ to 2.680$) \mu \mathrm{g} /$ $\mathrm{kg} / \mathrm{min}$ and $4.821(95 \% \mathrm{Cl} 3.951$ to 7.017$) \mu \mathrm{g} / \mathrm{kg} / \mathrm{min}$ respectively

potential adverse effects in obstetric patients. Caution must be exercised if methoxamine is used in the obstetric patients because methoxamine has tendency to produce uterine hypertonia which may result in fetal distress and it could interact with oxytocic drugs, subsequently result in postpartum hypertension [26]. In addition, the effect of methoxamine on uteroplacental flow is also controversial. Wright et al. demonstrated that methoxamine was associated with significant increase in uteroplacental resistance and flow [15], whereas Mintzer et al. showed methoxamine had no effect on uterine blood flow and the fetal arterial perfusion pressure [27]. Because these side effects of methoxamine in obstetrics are potential and controversial, we think it is also safe for obstetric patients. But there are insufficient supporting studies, so more data should be required before the use of methoxamine can be recommended in routine clinical practice for obstetric patients.

Several studies about phenylephrine showed that continuous infusion was superior to an IV bolus at preventing hypotension, nausea and vomiting and other intraoperative adverse events [5, 28, 29]. Similarly, a single intramuscular or intravenous injection for methoxamine has also been shown to have a slow onset and to cause unstable hemodynamics [8, 14]. In a previous study, they found that continuous intravenous infusion of methoxamine $(2 \mu \mathrm{g} / \mathrm{kg} / \mathrm{min})$ can provide safe and effective maintenance of hemodynamics under epidural anesthesia during hip-joint replacement surgery in elderly patients [13]. However, now we found no other studies about optimal dose of prophylactic fixed-rate methoxamine for obstetric patients. Similar to the study by Xiao F et al. [30], we studied four prophylactic fixed rates for methoxamine infusion based on patient body weight during cesarean delivery under combined spinalepidural anesthesia. Meanwhile the incidences of hypotension, hypertension and the number of physician interventions required were compared among 4 groups. Within a certain weight range (e.g. $60 \mathrm{~kg}$ to $80 \mathrm{~kg}$ ), a fixrate infusion dose with weight based is more accurate than that regardless of weight [31]. So, the infusion approach in this study might avoid under dosing in some patients and overdosing in the other patients.

In this study, we found greater hemodynamic stability in the higher dose of methoxamine fixed rate infusion $(4 \mu \mathrm{g} / \mathrm{kg} / \mathrm{min})$. In fact, the incidence of hypotension decreased with the increase in dose of methoxamine. Correspondingly, the number of patients who required physician intervention was lower in patients who received the higher infusion dose in group M4. Unlike previous studies, the incidence of reactive hypertension was not high in our study. This result may be related to the mild effect of methoxamine on raising blood pressure [16]. Our study period (the period of continuous infusion of methoxamine) was not too long, which may also lead to the outcome of lower incidence of reactive hypertension.

Spinal-induced hypotension and the use of methoxamine can both cause bradycardia. This study showed there were no significant differences in bradycardia among the groups. This change in heart rate represents differences of the regulation of the autonomic nervous system among pregnant patients in response to spinal anesthesia [18]. Now more and more studies demonstrated heart rate variability can reflect the activity of the

Table 3 Neonatal outcomes

\begin{tabular}{|c|c|c|c|c|c|}
\hline & $\begin{array}{l}\text { Group M1 } \\
(n=20)\end{array}$ & $\begin{array}{l}\text { Group M2 } \\
(n=20)\end{array}$ & $\begin{array}{l}\text { Group M3 } \\
(n=20)\end{array}$ & $\begin{array}{l}\text { Group M4 } \\
(n=20)\end{array}$ & $P$ value \\
\hline Apgar score at $1 \mathrm{~min}$ & $9(8 \sim 10)$ & $9.5(8 \sim 10)$ & $10(9 \sim 10)$ & $10(9 \sim 10)$ & 0.008 \\
\hline Apgar score at $5 \mathrm{~min}$ & $10(10 \sim 10)$ & $10(10 \sim 10)$ & $10(10 \sim 10)$ & $10(10 \sim 10)$ & \\
\hline \multicolumn{6}{|c|}{ Umbilical arterial blood gases: } \\
\hline $\mathrm{pH}$ & $7.27 \pm 0.03$ & $7.28 \pm 0.02$ & $7.27 \pm 0.03$ & $7.28 \pm 0.02$ & 0.64 \\
\hline $\mathrm{PaO} 2(\mathrm{mmHg})$ & $17.5 \pm 4.2$ & $21.9 \pm 5.1$ & $21.3 \pm 4.4$ & $21.7 \pm 3.5$ & 0.005 \\
\hline $\mathrm{PaCO} 2,(\mathrm{mmHg})$ & $49.0 \pm 4.2$ & $46.2 \pm 4.0$ & $47.7 \pm 4.8$ & $44.7 \pm 3.3$ & 0.008 \\
\hline Base excess(mM) & $-1.2 \pm 0.8$ & $-1.1 \pm 0.7$ & $-1.1 \pm 0.7$ & $-1.6 \pm 0.8$ & 0.08 \\
\hline
\end{tabular}

Data are presented as mean \pm SD or median (range) 

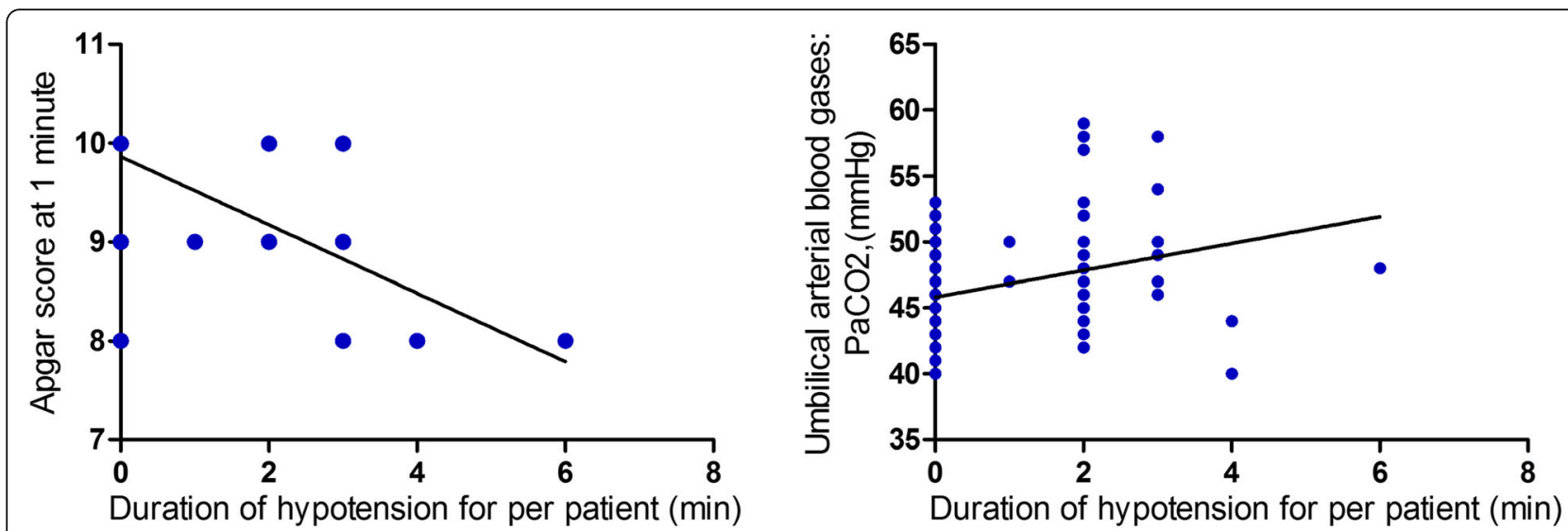

Fig. 5 Correlation analysis between duration of hypotension and 1-min Apgar score, duration of hypotension and umbilical arterial $\mathrm{PaCO} 2$ respectively

autonomic nervous system, and may be a tool to guide prophylactic therapy of patients at high risk for hypotension after spinal anesthesia. But this is beyond the scope of this article and requires further research.

Hypotension is believed to be the important etiological factor for intraoperative nausea and vomiting. Prophylactic methoxamine infusion regimens can also reduce the incidence of hypotension-induced nausea and vomiting [32]. There were no differences in the incidence of nausea and vomiting among the groups in our study, and our study was not powered to detect a significant association between methoxamine infusion dose and the incidence of nausea and vomiting too.

In our study, neonatal outcomes mainly included Apgar scores and umbilical arterial blood gases analysis. We found that 1-min Apgar scores and umbilical arterial $\mathrm{PaO} 2$ were lower, but umbilical arterial $\mathrm{PaCO} 2$ was higher in group M1. Some previous studies have mentioned duration of hypotension may be more important than severity of hypotension [3]. A transient decrease in blood pressure did not affect neonatal Apgar scores and the outcomes of umbilical arterial blood gases, whereas more than $4 \mathrm{~min}$ had a significant effect $[3,26]$. We suspected that the duration of hypotension might be associated with neonatal outcomes. Our study showed a negative correlation between duration of hypotension and 1-min Apgar score, but a positive correlation between duration of hypotension and umbilical arterial $\mathrm{PaCO}$. The results meant that long duration of hypotension may reduce oxygen supply to the fetus and increase fetal carbon dioxide production, leading to lower $\mathrm{PaO} 2$ and higher $\mathrm{PaCO} 2$ [33]. We did not find Apgar scores below 7 in this study, which meant that the newborns were still within compensation range.

The present study has a number of limitations. First, we collected hemodynamic data for only the first $12 \mathrm{~min}$ at 1-min intervals in this study. So it is possible for us to miss hemodynamic changes in later periods that may affect our final outcomes. Second, the hemodynamic data in our study mainly included only maternal SBP and HR; we did not measure other hemodynamic variables such as maternal cardiac output. Third, the study was limited in the healthy pregnant patients undergoing elective cesarean delivery; further research must focus on the high- risk parturients. Finally, for descriptive purposes we included a large number of secondary outcomes which were not the primary objective of this study. In order to reduce the impact of possible false positive conclusions, most of the secondary outcomes should be considered as exploratory only.

\section{Conclusion}

In conclusion, the present study demonstrated that the $\mathrm{ED}_{50}$ and $\mathrm{ED}_{95}$ of prophylactic methoxamine infusion for preventing spinal-induced hypotension in obstetric patients were 2.178 (95\% CI 1.564 to 2.680$) \mu \mathrm{g} / \mathrm{kg} / \mathrm{min}$ and 4.821 (95\% CI 3.951 to 7.017$) \mu \mathrm{g} / \mathrm{kg} / \mathrm{min}$, respectively. Moreover, it is seemed that the higher dose of methoxamine administered as fixed rate, the more maternal hemodynamic stability and the better neonatal outcomes might be got. In order to confirm these issues, further studies are needed to investigate the application of methoxamine in obstetrics.

\section{Abbreviations}

ASA: American Society of Anesthesiologists physical status; SBP: Systolic blood pressure; HR: Maternal heart rate; LR: Lactated Ringer's solution; SA: Spinal anesthesia; GA: Gestational age; I-D interval: Induction-delivery interval; U-D interval: Uterine incision-delivery interval

Acknowledgements

The authors would thank all staff in the Department of Anesthesia and Operating Room of the Women's Hospital, School of Medicine, Zhejiang University, China, for their help in this study. 


\section{Authors' contributions}

FF conducted the study and wrote the manuscript; TYW and $\mathrm{CH}$ took part in the study and collected the data; JCC and MN performed data analysis; CXZ designed the study and wrote the manuscript. All authors have read and approved the final manuscript, and ensured that this is the case.

\section{Funding}

The present study was supported by National Natural Science Foundation of China (NSFC, No 81471126). The financial support aids in data collection and writing the manuscript.

\section{Availability of data and materials}

The data that support the findings of this study in form of Excel files are available from the corresponding author.

\section{Ethics approval and consent to participate}

This study was preapproved by the ethical review board of the Women's Hospital, School of Medicine, Zhejiang University (approval number 20180095), written informed consent was obtained from all subjects participating in the trial

\section{Consent for publication}

Not applicable.

\section{Competing interests}

The authors declare that they have no competing interests.

Received: 29 November 2019 Accepted: 6 August 2020 Published online: 12 August 2020

\section{References}

1. Lee JE, George RB, Habib AS. Spinal-induced hypotension: incidence, mechanisms, prophylaxis, and management: summarizing 20 years of research. Best Pract Res Clin Anaesthesiol. 2017;31(1):57-68.

2. Tanaka M, Balki M, Parkes RK, Carvalho JC. ED95 of phenylephrine to prevent spinal-induced hypotension and/or nausea at elective cesarean delivery. Int J Obstet Anesth. 2009;18(2):125-30.

3. Kinsella SM, Carvalho B, Dyer RA, Fernando R, McDonnell N, Mercier FJ, Palanisamy A, Sia ATH, Van de Velde M, Vercueil A, Consensus Statement C. International consensus statement on the management of hypotension with vasopressors during caesarean section under spinal anaesthesia. Anaesthesia. 2018;73(1):71-92.

4. Ngan Kee WD. The use of vasopressors during spinal anaesthesia for caesarean section. Curr Opin Anaesthesiol. 2017;30(3):319-25.

5. Heesen M, Kolhr S, Rossaint R, Straube S. Prophylactic phenylephrine for caesarean section under spinal anaesthesia: systematic review and metaanalysis. Anaesthesia. 2014;69(2):143-65.

6. Ngan Kee WD. A random-allocation graded dose-response study of norepinephrine and phenylephrine for treating hypotension during spinal Anesthesia for Cesarean delivery. Anesthesiology. 2017;127(6):934-41.

7. Thiele RH, Nemergut EC, Lynch C 3rd. The physiologic implications of isolated alpha(1) adrenergic stimulation. Anesth Analg. 2011;113(2):284-96.

8. Thiele RH, Nemergut EC, Lynch C. The clinical implications of isolated alpha(1) adrenergic stimulation. Anesth Analg. 2011;113(2):297-304.

9. Jensen BC, Swigart PM, Laden ME, DeMarco T, Hoopes C, Simpson PC. The alpha-1D is the predominant alpha-1-adrenergic receptor subtype in human epicardial coronary arteries. J Am Coll Cardiol. 2009;54(13):1137-45.

10. Israilova M, Tanaka T, Suzuki F, Morishima S, Muramatsu I. Pharmacological characterization and cross talk of alpha1a- and alpha1b-adrenoceptors coexpressed in human embryonic kidney 293 cells. J Pharmacol Exp Ther. 2004;309(1):259-66.

11. Tsujimoto G, Tsujimoto A, Suzuki E, Hashimoto K. Glycogen-phosphorylase activation by 2 different alpha-1-adrenergic receptor subtypes methoxamine selectively stimulates a putative alpha-1-adrenergic receptor subtype (alpha-1a) that couples with ca2+ influx. Mol Pharmacol. 1989;36(1): 166-76.

12. Abdulla MH, Sattar MA, Johns EJ, Abdullah NA, Khan MAH. Evidence for the role of alpha(1A)-adrenoceptor subtype in the control of renal haemodynamics in fructose-fed Sprague-Dawley rat. Eur J Nutr. 2011;50(8): 689-97.
13. Sun D, Wu Y, Yang L, Han J, Liu R, Wang L. Effects of continuous intravenous infusion of methoxamine on the intraoperative hemodynamics of elderly patients undergoing total hip arthroplasty. Med Sci Monit. 2014; 20:1969-76.

14. Sun S, Sun D, Yang L, Han J, Liu R, Wang L. Dose-dependent effects of intravenous methoxamine infusion during hip-joint replacement surgery on postoperative cognitive dysfunction and blood TNF-alpha level in elderly patients: a randomized controlled trial. BMC Anesthesiol. 2017;17(1):75.

15. Wright PM, et al. Vasopressor therapy for hypotension during epidural anesthesia for cesarean section: effects on maternal and fetal flow velocity ratios. Anesth Analg. 1992;75:56-63.

16. Luo XJ, Zheng M, Tian G, Zhong HY, Zou XJ, Jian DL. Comparison of the treatment effects of methoxamine and combining methoxamine with atropine infusion to maintain blood pressure during spinal anesthesia for cesarean delivery: a double blind randomized trial. Eur Rev Med Pharmacol Sci. 2016;20(3):561-7.

17. Chen $X Z$, Chen H, Lou AF, Lu CC. Dose-response study of spinal hyperbaric ropivacaine for cesarean section. J Zhejiang Univ Sci B. 2006;7(12):992-7.

18. Hanss $R$, Bein B, Francksen $H$, Scherkl W, Bauer M, Doerges V, Steinfath M, Scholz J, Tonner PH. Heart rate variability-guided prophylactic treatment of severe hypotension after subarachnoid block for elective cesarean delivery. Anesthesiology. 2006;104(4):635-43.

19. Kuhn JC, Hauge TH, Rosseland LA, DahI V, Langesaeter E. Hemodynamics of phenylephrine infusion versus lower extremity compression during spinal Anesthesia for Cesarean delivery: a randomized, double-blind, PlaceboControlled Study. Anesth Analg. 2016;122(4):1120-9.

20. Ryu KH, Song K, Lim TY, Choi WJ, Kim YH, Kim HS. Does Equi-minimum alveolar concentration value ensure equivalent analgesic or hypnotic potency?: a comparison between Desflurane and Sevoflurane. Anesthesiology. 2018;128(6):1092-8.

21. Campbell JP, Stocks GM. Management of hypotension with vasopressors at caesarean section under spinal anaesthesia - have we found the holy grail of obstetric anaesthesia? Anaesthesia. 2018;73(1):3-6

22. McDonnell NJ, Paech MJ, Muchatuta NA, Hillyard S, Nathan EA. A randomised double-blind trial of phenylephrine and metaraminol infusions for prevention of hypotension during spinal and combined spinal-epidural anaesthesia for elective caesarean section. Anaesthesia. 2017;72(5):609-17.

23. Onwochei DN, Ngan Kee WD, Fung L, Downey K, Ye XY, Carvalho JCA. Norepinephrine intermittent intravenous boluses to prevent hypotension during spinal Anesthesia for Cesarean delivery: a sequential allocation dosefinding study. Anesth Analg. 2017;125(1):212-8.

24. Ngan Kee WD, Lee SWY, Ng FF, Khaw KS. Prophylactic Norepinephrine Infusion for Preventing Hypotension During Spinal Anesthesia for Cesarean Delivery. Anesth Analg. 2018;126(6):1989-94.

25. Nag DS, Samaddar DP, Chatterjee A, Kumar H, Dembla A. Vasopressors in obstetric anesthesia: a current perspective. World J Clin Cases. 2015;3(1):5864.

26. Morgan $P$. The role of vasopressors in the management of hypotension induced by spinal and epidural anaesthesia. Can J Anaesth. 1994;41(5 Pt 1): 404-13

27. Minzter BH, Johnson RF, Paschall RL, Ramasubramanian R, Ayers GD, Downing JW. The diverse effects of vasopressors on the fetoplacental circulation of the dual perfused human placenta. Anesth Analg. 2010;110(3): 857-62.

28. das Neves JF, Monteiro GA, de Almeida JR, Sant'Anna RS, Bonin HB, Macedo CF. Phenylephrine for blood pressure control in elective cesarean section: therapeutic versus prophylactic doses. Rev Bras Anestesiol. 2010:60(4):391-8.

29. Bishop DG, Cairns C, Grobbelaar M, Rodseth RN. Prophylactic phenylephrine infusions to reduce severe spinal Anesthesia hypotension during Cesarean delivery in a resource-constrained environment. Anesth Analg. 2017;125(3): 904-6.

30. Xiao F, Shen B, Xu WP, Feng Y, Ngan Kee WD, Chen XZ. Dose-response study of 4 weight-based phenylephrine infusion regimens for preventing hypotension during Cesarean delivery under combined spinal-epidural Anesthesia. Anesth Analg. 2020;130(1):187-93.

31. Pai MP. Drug dosing based on weight and body surface area: mathematical assumptions and limitations in obese adults. Pharmacotherapy. 2012;32(9): 856-68.

32. Choudhary M, Bajaj JK. Study comparing phenylephrine bolus and infusion for maternal hypotension and neonatal outcome during Cesarean section under spinal Anesthesia. Anesth Essays Res. 2018;12(2):446-51. 
33. Cooper DW, Gibb SC, Meek T, Owen S, Kokri MS, Malik AT, Koneti KK. Effect of intravenous vasopressor on spread of spinal anaesthesia and fetal acidbase equilibrium. Br J Anaesth. 2007;98(5):649-56.

\section{Publisher's Note}

Springer Nature remains neutral with regard to jurisdictional claims in published maps and institutional affiliations.

Ready to submit your research? Choose BMC and benefit from:

- fast, convenient online submission

- thorough peer review by experienced researchers in your field

- rapid publication on acceptance

- support for research data, including large and complex data types

- gold Open Access which fosters wider collaboration and increased citations

- maximum visibility for your research: over $100 \mathrm{M}$ website views per year

At $\mathrm{BMC}$, research is always in progress. 